\title{
O FEMINISMO DE PRIMEIRA ONDA NO INTERIOR DE MINAS GERAIS PELAS MÃOS DE MARIA DE LOURDES TEIXEIRA
}

\section{THE FIRST WAVE FEMINISM IN THE INTERIOR OF MINAS GERAIS BY THE HANDS OF MARIA DE LOURDES TEIXEIRA}

\author{
Simone Maria dos Santos ${ }^{1}$ \\ Nayara Aparecida de Moura ${ }^{2}$
}

\begin{abstract}
RESUMO
Durante séculos, as mulheres foram apagadas da História; sem sobrenome, participação efetiva ou voz ativa, elas se comparavam a fantasmas que andavam pelo mundo sem deixar rastros. Contra este cenário, emerge, na Europa do século XVIII, o Feminismo de Primeira Onda e, em consonância com este movimento, no século XIX, têm-se a Primeira Onda do Feminismo no Brasil. As feministas utilizaram as letras como estratégia de militância na luta pela emancipação feminina e pela conquista de direitos. Adentrando gradualmente no universo jornalístico tradicionalmente masculino, as mulheres ganharam visibilidade, força e espaço para suas lutas de gênero. Nessa perspectiva, buscou-se investigar e analisar a primeira onda do movimento feminista no interior de Minas Gerais, na cidade de Divinópolis, a partir dos escritos de Maria de Lourdes Teixeira, professora e escritora, no jornal A Estrella da Oeste entre 1922 e 1923.
\end{abstract}

Palavras-chave: Movimento Feminista de Primeira Onda; Jornais; Igualdade de Gênero; Escrita Feminina.

\begin{abstract}
For centuries, the women were erased from the History; without surname, effective participation or active voice, the women compared themselves to ghosts that walk through the world without leaving traces. With the emergence of the First Wave of Feminism in Brazil, and in the world, feminists used letters as a strategy of militancy in the struggle for feminine emancipation and for the conquest of rights. Gradually entering the traditionally male journalistic universe, women gained visibility, strength and space for their gender struggles. In this perspective, we seek to investigate and analyze the first wave of the feminist movement in the interior of Minas Gerais, in Divinópolis, from the writings of Maria de Lourdes Teixeira, teacher and writer in the newspaper A Estrella da Oeste. during 1922 and 1923.
\end{abstract}

Keywords: First Wave of Feminist Movement; Newspapers; Gender Equality; Women's Writing.

\footnotetext{
${ }^{1}$ Pós-Doutora no Programa de Demografia da Faculdade de Ciências Econômicas da Universidade Federal de Minas Gerais (UFMG). Doutora em Sociologia pela Universidade Federal de Minas Gerais (UFMG). Professora Associada da Universidade do Estado de Minas Gerais (UEMG).

${ }^{2}$ Mestranda em Gênero pela Universidad Catolica de Cuyo. Graduada em História pela Universidade do Estado de Minas Gerais (UEMG). Email: nayaraapm@gmail.com.
} 


\section{Revista (O) \\ Debates Insubmissos}

\section{INTRODUÇÃOO}

Em um contexto de hipermodernidade ou globalização (LIPOVESTKY, 2010; IANNI, 1998) onde predominam as tecnologias digitais, os movimentos feministas ganham cada vez mais espaço e força nas mídias sociais (Facebook, Instragram, Whatsapp, Tumblr...). Nesse sentido, com a crescente onda do ciberfeminismo, é possível ressaltar a importância das letras para a visibilidade e disseminação dos ideários feministas. Os famosos "textões da internet" (MADURO, 2017), que em grande medida, abordam questões relacionadas à igualdade de gênero; ao serem propagados, vão criando uma rede de comunicação que rompe as barreiras entre o público e o privado, fazendo com que as informações circulem com certa fluidez.

Uma rede de comunicação e interação por onde as ideias circulam, criada através das letras escritas, foi a principal estratégia de militância do chamado Feminismo de Primeira Onda no final do século XVIII e século XIX, período em que o movimento feminista emergia e começava a se consolidar como movimento social. Porém, nesse momento, as militantes lidavam com vários problemas ligados diretamente à escrita: a alta taxa de analfabetismo feminino, o controle das letras pelos homens (jornalistas, juristas e políticos) e a falta de direitos básicos como o acesso à educação e o direito ao voto.

Diante dos problemas enfrentados pelas mulheres no período, torna-se importante elencar alguns questionamentos. Como propagar abertamente as questões sociais numa época em que não existia internet, televisão ou rádio? Como lutar pelos direitos civis de uma determinada classe quando nenhuma lei vigente abrangia essa classe? Como instruir mulheres em um período onde elas não tinham acesso à educação? Como reunir e mobilizar um grupo de mulheres para que lutassem juntas por seus direitos num contexto onde elas não tinham autonomia nem para escolher o próprio marido? Ou mesmo se iriam se casar?

Assim, falar sobre Feminismo de Primeira Onda no Brasil é falar, ao mesmo tempo, de uma história não contada e de uma história vitoriosa. Uma história não contada, porque muito pouco se fala desse início histórico do movimento, e uma história vitoriosa porque todas as pautas pelas quais elas lutaram, como: o direito ao trabalho, o direito à educação básica e superior, o direito de votar e ser votada, o direito de participar de concursos públicos, a 
legalização do divórcio (MARQUES, 2006; PINTO, 2003; TELLES, 1993) foram, mais cedo ou mais tarde, alcançadas.

A partir dos termos supracitados, o presente artigo tem como objetivo investigar e analisar a Primeira Onda do Movimento Feminista no Brasil, tendo como foco os escritos de Maria de Lourdes Teixeira no jornal A Estrella da Oeste durante os anos de 1922 e 1923, na cidade de Divinópolis, interior de Minas Gerais, bem como sua interação no jornal com outras escritoras. Maria de Lourdes Teixeira era conhecida como Lurlurde, foi mãe, professora, diretora, escritora e uma importante militante da causa feminista na cidade durante a década de 1920.

\section{ONDE ESTÃO AS MULHERES NA HISTÓRIA?}

Antes de adentrar na História do Feminismo, cabe evidenciar a importância e os desafios enfrentados por aqueles que tentaram escrever sobre uma História das Mulheres. Segundo Perrot (2007), na maior parte das sociedades ocidentais e orientais, a invisibilidade e o silêncio da mulher faz parte da "ordem natural” das coisas. Essa é a garantia de uma cidade em paz e ordenada; seu aparecimento, individual ou coletivo amedronta. Até mesmo o corpo feminino amedronta, por isso que é mais adequado que ele esteja coberto de roupas ou de véus.

Dito de outra forma, os homens são descritos como indivíduos, pessoas, trazem sobrenomes que são transmitidos a sua prole criando ascendências e descendências. As mulheres, por sua vez, não são narradas com sobrenome, não aparecem com a prerrogativa de transmitir algo a prole, não apresentam linhagens. Elas são colocadas como bens de aquisição no mercado matrimonial; enquanto propriedades de seu pai, e após o casamento, se tornam propriedades de seu marido. Nesse sentido, Bourdieu (2012) afirma:

O princípio da inferioridade e da exclusão da mulher, que o sistema míticoritual ratifica e amplia, a ponto de fazer dele o princípio de divisão de todo o universo, não é mais que a dissimetria fundamental, a do sujeito e do objeto, do agente e do instrumento, instaurada entre o homem e a mulher no terreno das trocas simbólicas, das relações de produção e reprodução do capital simbólico, cujo dispositivo central é o mercado matrimonial, que estão na base de toda a ordem social: as mulheres só podem aí ser vistas como 


\section{Revista (O) \\ Debates Insubmissos}

objetos, ou melhor, como símbolos cujo sentido se constitui fora delas e cuja função é contribuir para a perpetuação ou o aumento do capital simbólico em poder dos homens (BOURDIEU, 2012, p. 55).

Como são pouco vistas na sociedade, pouco se fala sobre elas e em consequência, pouco se preserva delas também. Há um silêncio das mulheres na História que oriunda do silêncio feminino nas próprias fontes históricas. As mulheres deixaram poucos vestígios diretos, escritos ou materiais, em primeiro lugar porque, em grande escala, seu acesso à educação foi negado durante séculos. Sem saber ler e escrever as produções que demonstram sua visão de mundo como diários, cartas ou livros de receita simplesmente não existem.

Em segundo lugar porque, as poucas produções que possuíam eram destruídas por elas mesmas, apagando seus vestígios por julgá-los sem interesse (PERROT, 2007). Isto porque em várias situações durante suas vidas, as mulheres foram convencidas de que eram "apenas" mulheres, e a forma com que viviam, pensavam e agiam e interagiam não tinha significância nenhuma.

A língua escrita e falada, especialmente os idiomas que se originam do latim, também contribuíram para o silêncio feminino nas fontes. Sempre que há uma mistura de gêneros, emprega-se um plural masculino: "eles" substitui "elas", não há um gênero neutro para coletivos mistos (PERROT, 1998). Assim, em termos como a greve de professores, a manifestação de alunos, a resistência dos trabalhadores, absorve-se gramaticalmente a presença das mulheres no cotidiano e nas fontes históricas.

Por outro lado, quando as mulheres são vistas num determinado espaço público, elas são enxergadas pelos homens como um coletivo natural, fato que corresponde a seus modos de intervenção coletiva. Ignora-se o individual feminino e a condição singular humana da mulher para que se materialize um coletivo de qualidade e estereótipos: mães, donas-de-casa, anciãs, histéricas, vadias, entre outros.

Em contrapartida a esse silêncio estabelecido das fontes, existe um excesso de discursos e representações sobre as mulheres feitas por homens de todos os tempos: textos, pinturas, esculturas e fotografias. Representações sobre o que as mulheres são e de como elas devem se comportar, abordando sempre a visão e o imaginário masculino sobre a mulher (PERROT, 1988). 
Georges Duby, na introdução do livro Images de femmes, enfatiza o que significava, para ele, uma obsessão enigmática: a força da iniciativa masculina que reduz as mulheres a espectadoras, mais ou menos submissas, de si mesmas. "As mulheres não representavam a si mesmas, escreve ele. Elas eram representadas." (DUBY, 1992 apud PERROT, 2007, p. 23).

\section{UMA HISTÓRIA PARTIDÁRIA}

Ao se analisar a produção historiográfica, ao longo dos séculos, percebe-se que a História é o produto de um determinado meio teórico e social. De forma ampla, Michel De Certeau (1982) define a escrita da História, através do que ele denomina de operação historiográfica, como o "resultado da ação conjunta de três componentes distintos: o lugar (meio social/econômico, um ambiente político/cultural, uma profissão), os procedimentos de análise (teorias próprias da disciplina) e a construção de um texto (uma literatura)" (CERTEAU, 1982, p. 56).

Durante o século XX, a História, junto das outras ciências humanas, sofreu uma drástica mudança no que concerne a seu lugar socioeconômico. Em meio aos sangrentos acontecimentos do período, os historiadores europeus começaram a voltar seus olhares para as temáticas de grupos sociais esquecidos e oprimidos, que antes eram excluídos de seu interesse. Entre esses grupos sociais excluídos estavam às mulheres.

De fato, alguns historiadores e teóricos sociais desenvolveram estudos sobre as mulheres antes da citada transformação historiográfica do século XX. Porém, em suma maioria, esses teóricos mantiveram a abordagem sobre elas de acordo com os pensamentos dominantes em seu tempo. Paulo (5 d.C. - 67 d.C.), apóstolo de Cristo, proibiu, em sua carta a Timóteo, que as mulheres ensinassem nos templos ou usassem de autoridade sobre o marido. A elas, cabia apenas o silêncio porque primeiro foi formado Adão e só depois Eva (BÍBLIA DE JERUSALÉM, 2000).

Essa concepção da mulher como algo caótico, fraco, destruidor da ordem, um objeto a ser dominado, aparece também entre filósofos e teóricos do pós- iluminismo. Para o filósofo alemão Hegel (1967), as mulheres eram passíveis de educação, mas não tinham capacidades 
intelectuais para desenvolverem atividades que demandassem uma faculdade universal como as ciências avançadas, a filosofia e certas formas de produção artística (HEGEL, 1967).

Pierre-Joseph Proudhon (1858), filósofo político e economista francês, alegava que as mulheres possuíam uma predisposição natural à destruição já que eram intelectualmente inferiores em relação aos homens; elas eram dotadas de ideias desconexas, raciocínios ilógicos, ilusões tomadas por realidade. Por isso, era justo que na assembleia geral, o voto masculino contasse por 9 enquanto o voto feminino contasse por 4 (PROUDHON, 1858).

O historiador francês Michelet (1981) via na relação dos sexos um dos motores essenciais para o funcionamento da história. Segundo ele, na medida em que a mulher aspirasse à atuação no âmbito público, usurpando os papeis masculinos, haveria uma transmutação de força do mal e de infelicidade, dando lugar ao total desequilíbrio da história (MICHELET, 1981). “O estruturalismo antropológico de Claude Lévi-Strauss insistia no papel da mulher na reprodução e no parentesco: Troca de bens, troca de mulheres" (PERROT, 2007, p. 15 ).

$\mathrm{Na}$ suposta neutralidade dicotômica entre o masculino e o feminino, resultado das observações dos fenômenos naturais, a sociedade foi gradualmente se organizando e estabelecendo papéis hierárquicos. Houve a afirmação de um elemento forte e de um elemento fraco, um extremo que domina e outro extremo que obedece, algo que representa a norma e algo que personifica a divergência. A hierarquia é instalada porque um dos pares, de acordo com seu sexo, se coloca como modelo a seguir enquanto o outro é visto como negação ou falha. "É na inicial complementaridade que se insinua a diferença" (BEAUVOIR,1949, p. 13).

Inerente a essa sociedade hierárquica, a filosofia vem como a expressão de um modelo que se impõe, um modelo masculino, já que ela foi inicialmente pensada por homens e teve os homens como receptores. Os filósofos, e posteriormente os pensadores sociais e políticos, criaram teorias para explicar cientificamente a submissão e a inferioridade das mulheres.

Essas teorias foram aceitas, disseminadas e reproduzidas em várias sociedades e culturas como "verdades universais". Portanto, ainda que a mulher aparecesse nas teorias e estudos filosóficos/sociais antes da reviravolta das ciências humanas do século XX, elas eram 


\section{Revista \\ Debates Insubmissos}

retratadas como um desvio, um erro, ou numa hipótese mais moderada, como algo diferente, ou seja, como "outro".

Além disso, a corrente positivista da História no século XIX provocou um recuo nas abordagens sobre a mulher. Devido a seu interesse exclusivo pela história política e pelo domínio público, as fontes escolhidas para se "fazer história" eram as fontes administrativas, as diplomáticas e os documentos militares, ambientes nos quais as mulheres pouco apareciam.

A Escola dos Annales, já no século XX, propôs uma abordagem diferente para a historiografia: se desvencilhar das realidades abstratas e voltar o olhar histórico para o cotidiano, a história de pessoas comuns. Mesmo que os Annales não tivessem de fato incorporado as mulheres dentro da historiografia, eles foram grandes colaboradores para que essa prática acontecesse num futuro próximo.

As correntes revisionistas marxistas da década de 1960, vinculadas ao movimento da história social, começaram a produzir estudos sobre os grupos ultrapassados pela história, as massas populares sem um nível organizacional significativo, e também, as mulheres do povo (SOIHET, 1997).

A onda crescente do movimento feminista da década de 1960 e 1970 foi o fator principal para que verdadeiramente surgisse a História das Mulheres. Michelle Perrot (2007) afirma que o desenvolvimento da História das Mulheres acompanha em surdina o "movimento" das mulheres em direção à emancipação e à liberação. Trata-se da tradução e do efeito de uma tomada de consciência ainda mais vasta: a da dimensão sexuada da sociedade e da História.

\section{METODOLOGIA}

Uma vez estabelecida à relação existente entre o campo historiográfico e a história das mulheres cabe pontuar a metodologia que norteou o desenvolvimento deste trabalho: a análise de imprensa - jornais. Em relação à pesquisa em periódicos, é importante que, de início, se tenha informações sobre a história do jornal pesquisado, quando e porque começou a ser produzido, quais ideologias permeavam o jornal, quem escrevia e quem lia, qual contexto 


\section{Revista \\ Debates Insubmissos}

político, histórico e social que ele estava inserido. Conhecer os caminhos por onde o jornal passou é essencial para uma análise mais densa do mesmo.

[...] a Imprensa é rica em dados e elementos, e para alguns periódicos é a única fonte de reconstituição histórica, permitindo um melhor conhecimento das sociedades ao nível de suas condições de vida, manifestações culturais e políticas, etc. Seu estudo é enriquecedor, sobretudo quando se tem interesse pela História Social, História das Mentalidades e História das Ideologias [...] a imprensa age sempre no campo político-ideológico e, portanto, toda pesquisa realizada a partir da análise de jornais e periódicos deve necessariamente traçar as principais características dos órgãos de Imprensa consultados (ZICMAN, 1985, p. 89-90).

Sendo o jornal um meio de comunicação de massa, é necessário que a análise periódica atravesse esse conceito. Thompson (2002) define comunicação de massas como uma produção institucional, difusa e envolvida de bens simbólicos por meio da transmissão e armazenamento da informação a uma grande quantidade de receptores, mas adverte que:

[...] o termo "massa" não deve ser tomado em termos estritamente quantitativos; o ponto importante sobre comunicação de massa não é que um determinado número ou proporção de pessoas receba os produtos, mas que os produtos estão, em princípio, disponíveis a uma pluralidade de receptores (THOMPSON, 2002, p. 287).

No que concerne aos procedimentos metodológicos na pesquisa em imprensa, é importante ressaltar que o que objeto de análise é uma fonte primária, as publicações de um jornal sobre determinado assunto, num determinado período, reflete o pensamento político/histórico/social da época. Além do que, o jornal interfere e contribui para a formação cultural das pessoas, sendo agente e objeto ao mesmo tempo. Assim, Capelato (1988) afirma que:

A imprensa constitui um instrumento de manipulação de interesses e intervenção na vida social. Partindo desse pressuposto, o historiador busca estudá-la como agente da história e captar o movimento vivo das ideias e personagens que circulam pelas páginas dos jornais [...]. Na construção do fato jornalístico interferem não apenas elementos subjetivos de quem o produz, mas também os interesses aos quais o jornal está vinculado. $\mathrm{O}$ historiador, ao estudar a imprensa, tem que levar em conta esses aspectos. Questionar a imagem "imprensa, espelho fiel da realidade", implica um trabalho de reconstituição do real em suas múltiplas facetas (CAPELATO, 1988, p. 21-22). 
Em relação à inserção social que o jornal proporcionava, a escrita feminina equivalia ao ingresso das mulheres no grupo dos cidadãos ativos (GOMES, 2009). Excluídas de participarem efetivamente da vida social das cidades, impossibilitadas de ocuparem cargos públicos e de assegurarem dignamente a própria subsistência; impedidas de ter acesso à educação superior. As mulheres no século XIX estavam confinadas ao espaço privado, fechadas dentro de casas, mocambos e senzalas, construídos por pais, maridos, senhores (TELLES, 2004). Essa divisão sexual dos espaços, tida como "ordem social" funcionar como um mecanismo de repressão e dominação feminina:

A ordem social funciona como uma imensa máquina simbólica que tende a ratificar a dominação masculina sobre a qual se alicerça: é a divisão social do trabalho, distribuição bastante estrita das atividades atribuídas a cada um dos dois sexos, de seu local, seu momento, seus instrumentos; é a estrutura do espaço, opondo o lugar de assembleia ou de mercado, reservados aos homens, e a casa, reservada às mulheres; ou, no interior desta, entre a parte masculina, com o salão, e a parte feminina, com o estábulo, a água e os vegetais; é a estrutura do tempo, a jornada, o ano agrário, ou o ciclo de vida, com momentos de ruptura, masculinos, e longos períodos de gestação, femininos (BOURDIEU, 2012, p. 18).

Ao adentrar no universo jornalístico tradicionalmente masculino, além de romper com os limites do privado, as mulheres utilizaram o jornal como um meio de politização do cotidiano feminino, se inserindo gradualmente nos debates políticos da época e lutando por seus direitos (GOMES, 2009). Os periódicos se transformaram em veículos onde as mulheres se expressavam, construíam seus pontos de vista e suas representações sobre si mesmas, tornando sua "fala" pública e, em alguns casos, mobilizadora. Dito de outra forma, o jornal retrata todo um contexto político, histórico, cultural e social, ao mesmo tempo em que engloba elementos subjetivos de quem escreve.

\section{O "NASCIMENTO" DO FEMINISMO:}

É importante definir que o feminismo é um conceito bastante flexível e complexo que abrange processos de transformações, rompimentos e resistências. Devido à grande diversidade de posicionamentos, muitas autoras utilizam o termo feminismos no plural em 
oposto ao feminismo no singular (CASTRO, 2000; COSTA e SARDENBERG, 1994; RAGO, 2006; SOIHET, 2006). A abordagem plural dessas autoras não está relacionada apenas à apresentação das diferenças dentro dos feminismos, mas em reconhecer e valorizar cada aspecto particular como uma grande riqueza para o movimento. Os feminismos de cada época, em cada cultura, com as diversas estratégias de militância utilizadas e os vários seguimentos teóricos sociais, foram importantes nas lutas em favor à igualdade de gêneros e à emancipação feminina.

Para esta pesquisa em particular, foi escolhido usar o termo feminismo no singular. Essa opção não se atrela a ideia de um movimento homogêneo, antagônico a história e culturalmente fixo, se baseia na compreensão de um segmento comum a todos os feminismos: a luta pela igualdade entre os gêneros, pela ressignificação do papel da mulher na sociedade e pela emancipação e autonomia das mulheres. Segundo Zirbel (2007), esse segmento comum pode ser encontrado em diversos grupos de diversos contextos históricos. As particularidades acontecem devido à interpretação das diferentes opressões vividas por cada grupo, inserido em cada momento histórico e nas estratégias adotadas para a superação das desigualdades e na conquista da emancipação desejada.

Segundo Costa e Sardenberg (2007), o feminismo como movimento social é em sua essência moderno, tem suas raízes atreladas aos ideais liberais de igualdade evidenciados na Revolução Francesa de 1789. Ainda que a igualdade fosse clamada para todos, o conceito na prática ficou limitado apenas às classes dominantes e, como bem estabeleceu a "Declaração dos Direitos do Homem", só entre os homens. Porém, o rompimento com o isolamento doméstico trazido pela Revolução Industrial e os trabalhos femininos fabris, juntamente com os ideais de igualdade circulantes no período, levaram as mulheres a perceberem a exploração e a opressão em que viviam.

Foi através da consciência dessa submissão que se originou o movimento feminista no final do século XVIII, sendo consolidado no século XIX, na maioria dos países europeus e nos Estados Unidos (COSTA; SARDENBERG, 2007, p. 25) e, posteriormente, nos países da América Latina, tendo seu auge na luta sufragista (COSTA, 2006, p. 51). 


\section{noviste

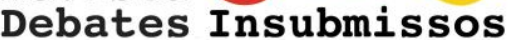

No Brasil, o pensamento feminista foi introduzido por Nísia Floresta Brasileira Augusta (1810-1885) no século XIX, nascida no Rio Grande do Sul e falecida em Paris. A publicação das obras: Conselhos à Minha Filha (1842), Opúsculo Humanitário (1853) e A Mulher (1856), junto com a tradução da obra pioneira de Mary Wollstonecraft, $A$ vindication of the Rights of Women (1832), simboliza o despertar de uma consciência crítica sobre a condição das mulheres na sociedade.

E aqui está a marca diferenciadora deste momento histórico: a nossa primeira onda, mais que todas as outras, vem de fora, de além mar, não nasce entre nós. E Nísia Floresta é importante principalmente por ter colocado em língua portuguesa o clamor que vinha da Europa, e feito a tradução cultural das novas ideias para o contexto nacional, pensando na mulher e na história brasileira. Ao se apropriar do texto europeu para superálo, ela se insere numa importante linhagem antropofágica da literatura brasileira, que desde Gregório de Matos estava inaugurada. Na deglutição geral das ideias estrangeiras, era comum promover-se uma acomodação das mesmas ao cenário nacional, e é o que ela faz. Tanto que o título de seu livro contém não apenas a ideia dos rights of woman, mas também "a injustiça dos homens" (COSTA; SARDENBERG, 2007, p. 25).

Essa primeira fase do feminismo é conhecida como Feminismo de Primeira Onda:

O feminismo, como movimento social visível, tem vivido algumas "ondas". O feminismo de "primeira onda" (no Brasil) teria se desenvolvido no final do século XIX e centrado na reivindicação dos direitos políticos - como o de votar e ser eleita -, nos direitos sociais e econômicos - como o de trabalho remunerado, estudo, propriedade, herança. O feminismo chamado de "segunda onda" surgiu depois da Segunda Guerra Mundial, e deu prioridade às lutas pelo direito ao corpo, ao prazer, e contra o patriarcado - entendido como o poder dos homens na subordinação das mulheres. Naquele momento, uma das palavras de ordem era: "o privado é político" (PEDRO, 2005, p.79).

A concepção de onda, como um evento, está definida em Kristeva (1979), ao ser feita distinção entre as gerações de feministas francesas antes e depois de 1968 (MACHADO, 1992). Porém, essa divisão tradicional dos movimentos feministas em ondas (primeira, segunda e terceira) recebe muitas críticas. Várias autoras defendem que pensar o movimento feminista a partir do conceito de ondas leva a entender que as reivindicações da primeira onda estavam completamente resolvidas quando se alcançou a segunda onda, num sentido progressista, ou que fora dos períodos abrangidos pelas ondas, houve um intervalo sem 


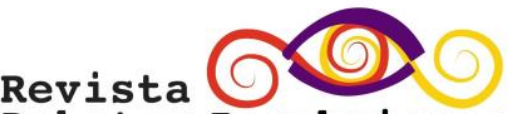 \\ Debates Insubmissos}

atividades. E ainda pode levar a ignorar o fato de que, existiram diversos tipos de movimentos feministas dentro da mesma onda. Nessa perspectiva, Costa (2009) afirma:

Diferenciados por conjunturas, os feminismos, assim, são vistos, em geral, como irrupções em que, de repente, não mais que de repente, mulheres diversas se juntam, mostram-se "irmanadas" na agitação de "causas" ou motivações políticas que se avolumam e que avançam como onda. Esta, depois de atingir um ponto alto, desce, invadindo os mais variados territórios, em diversos tempos; em seguida, tudo parece dissipar-se. Diria que um maior rigor na produção do conhecimento dessas "causas" /motivações depende, sim, de pesquisa de fontes, mas sob uma leitura orientada por conceitos que admitam esses movimentos conjunturais como partes de um vasto tecido social, em grande medida, submersas, vindas de diferentes tempos históricos, trançadas entre si e que avançam em infinitas combinações de "ramificações", continuadas ou não, sinalizando movimentos e transformações de visões de mundo, como nos sugere Joana Maria Pedro, ao recorrer ao mencionado conceito de rizoma (COSTA, 2009, p. 4 ).

Entretanto, na pesquisa foi escolhido trabalhar com o conceito de ondas no sentido de se constituir marcos temporais históricos. $\mathrm{O}$ que se postula é que, de acordo com o período tratado, os movimentos feministas apresentavam demandas específicas, que foram se transformando conforme as mudanças sociais, políticas e históricas. Essa divisão em ondas pode ser útil na realização de análises sobre os avanços alcançados pelos movimentos e sobre as mudanças e permanências dentro das práticas e das teorias feministas. Para que tais compreensões sejam alcançadas, é necessário conhecer o que abrange cada período histórico, que foi designado como uma onda do feminismo. Neste sentido, cabe descrever, mesmo que de forma sintética, o contexto do surgimento da primeira onda no Brasil. Ou seja, pontuar em que contexto a Primeira Onda é trazida para o Brasil.

Em 1808, a Corte Portuguesa foi transferida para o Rio de Janeiro e trouxe consigo reformas políticas e econômicas que abriram caminho para a Independência do Império. Houve algumas reformas no Império e novos hábitos foram instituídos. Aos poucos, o número de pessoas que frequentavam os espetáculos e compravam livros se ampliou, os romances e novelas europeus chegaram à cidade do Rio juntamente com a moda dos jornais e folhetins.

Em 1822, o jornal recifense Sentinela da Liberdade publicou um manifesto assinado por mais de 120 mulheres da Paraíba. Elas afirmavam que compunham "metade da sociedade 


\section{Revista \\ Debates Insubmissos}

humana" e que também desejavam reassumir os direitos que lhes haviam sido usurpados, "quebrando os vergonhosos ferros da vil escravidão em que jazíamos" (TELLES, 2004, p. 338). Por direito, elas disseram, queremos entrar na partilha e glória do Brasil.

É nesse período que surge a imprensa de mulheres, sendo o maior meio de divulgação das ideias feministas no Brasil. Telles (1993) afirma que o Brasil foi o país latino-americano onde houve maior empenho do jornalismo feminista. O primeiro desses jornais foi $O$ Jornal das Senhoras (1852) editado por Joana de Paula Manso; depois veio o Belo Sexo (1862) dirigido por Julia de Albuquerque Aguiar; e em seguida veio O Sexo Feminino (1873) editado por Francisca Senhorinha Diniz. Também teve O Eco das Damas (1879) de Amélia Carolina Couto; O Direito das Damas (1882) de Idalina D’Alcântara Costa; o jornal A Família (1888) de Josephina Alvares Azevedo e vários outros. Josephina também escreveu a peça teatral: $O$ Voto Feminino, em 1890, e teve grande sucesso de público no Rio de Janeiro (BANDEIRA; MELO, 2010, p. 13) em 23 de junho de 1893 - a apresentação foi noticiada por um jornal feminino em Paris (TELLES, 2004). Em relação a toda esta produção Muzart (2003) afirma que:

[...] no século XIX, as mulheres que escreveram, que desejaram viver da pena, que desejaram ter uma profissão de escritoras, eram feministas, pois só o desejo de sair do fechamento doméstico já indicava uma cabeça pensante e um desejo de subversão. E eram ligadas à literatura. Então, na origem, a literatura feminina no Brasil esteve ligada sempre a um feminismo incipiente (MUZART, 2003, p. 267).

Foram tantos jornais fundados por mulheres que buscavam esclarecer as leitoras e fazer reivindicações emancipatórias objetivas, que chegaram a formar uma rede, de norte a sul, atentos às publicações e ações das mulheres (TELLES, 2004). A principal causa abordada era o sufrágio, direito de votar e ser votada, mas esta não era à única reinvindicação em pauta.

Em todo o país houve a organização de associações femininas e manifestos em jornais voltados para a causa abolicionista (BANDEIRA; MELO, 2010); em favor do direito das mulheres ao acesso à educação (TELLES, 1993); a legalização do divórcio (MARQUES, 2006); o direito a participar de concursos e cargos públicos (TELLES, 1993) e outros. Essas mulheres, em grande parte, eram republicanas. Hahner (1981) defende que as aspirações das 


\section{Revista \\ Debates Insubmissos}

mulheres pela conquista de direitos jurídicos e políticos, foram estimuladas pelo pensamento republicano:

O fermento da agitação republicana dos fins da década de 1880 não apenas fortaleceu o desejo feminista por direitos políticos como também deu às mulheres argumentos adicionais em favor do sufrágio e oportunidades de procurar o voto. A Proclamação da República, em 15 de novembro de 1889, ofereceu inicialmente a possibilidade de uma estrutura política mais fluida e aberta, com a extensão do voto, em teoria, a todos os homens alfabetizados, a questão do sufrágio pôde tornar-se um tópico mais vital para as feministas cultas que experimentavam um sentimento de frustração e privação política (HAHNER, 1981, p. 80).

Ainda que a Mulher de Letras $^{3}$ (DUARTE, 2009) fosse a principal forma de militância feminista no século XIX e início do século XX, ela não foi à única. Houve uma intensa atividade das mulheres operárias que aderiram à ideologia anarquista, reunidas na União das Costureiras, Chapeleiras e Classes Anexas, reivindicando a igualdade salarial e de jornadas de trabalho entre homens e mulheres (PINTO, 2010).

Em 1910, o Partido Republicano Feminino foi fundando pela professora Deolina Dalho, em 1917 ela promoveu uma passeata com quase 100 mulheres a favor do voto feminino no Rio (TELLES, 1993). Em 1918, ao voltar de um longo período de estudos em Paris, a bióloga Bertha Lutz criou a Federação Brasileira para o Progresso Feminino - FBPF que tinha como objetivo promover as lutas jurídicas e políticas das mulheres da época (PINTO, 2003).

Em 1920 foi criada a Liga para a Emancipação Internacional da Mulher pela professora Maria Lacerda de Moura e Bertha Lutz, um grupo de estudos cuja militância principal era lutar pela igualdade política das mulheres (TELLES, 1993). Em 1922, após voltar dos Estados Unidos onde esteve representando o Brasil no Conselho Feminino da Organização Internacional do Trabalho e na I Conferencia Pan- Americana da Mulher, Bertha organizou o I Congresso Internacional Feminista no Rio de Janeiro (PINTO, 2003).

Elvira Komel, a primeira mulher mineira eleitora (1928), abriu a primeira banca feminina de advocacia em Belo Horizonte com apenas 23 anos de idade. Em 1930, Elvira

\footnotetext{
${ }^{3}$ Forma como ficou conhecida à militância feminista na primeira onda devido às quatro formas de inserção social do período: magistério, os salões, os jornais e a epistolografia.
} 
criou o Batalhão Feminino João Pessoa e alistou 8 mil mulheres que trabalharam na retaguarda do movimento revolucionário, ela promoveu o I Congresso Feminino Mineiro em 1931 e faleceu em 1932 (PINTO, 2003). Todas essas movimentações feministas resultaram na conquista de vários direitos às mulheres no Brasil, principalmente o de votar e ser votada em 1932:

Se lembrarmos que feminismo foi um movimento legítimo que atravessou várias décadas, e que transformou as relações entre homens e mulheres, torna-se (quase) inexplicável o porquê de sua desconsideração pelos formadores de opinião pública. Pode-se dizer que a vitória do movimento feminista [da época] é inquestionável quando se constata que suas bandeiras mais radicais tornaram-se parte integrante da sociedade, como, por exemplo, mulher frequentar universidade, escolher profissão [...], candidatar-se ao que quiser... Tudo isso, que já foi um absurdo sonho utópico, faz parte de nosso dia a dia e ninguém nem imagina mais um mundo diferente (DUARTE, 2003, p. 81).

Mesmo com todas essas conquistas feministas, diferente do que aconteceu em outros países, no Brasil houve uma forte resistência em relação à palavra feminismo. O movimento antifeminista do século XIX e XX foi muito "competente" ao disseminar socialmente a imagem da mulher feminista como oposta de feminina (DUARTE, 2003). Segundo Pedro (2013) até o final dos anos 1980, poucas mulheres aceitavam o rótulo de feminista, porque, no senso comum, ainda prevalecia à ideia de que o feminismo era uma luta de mulheres feias, lésbicas, ressentidas, masculinizadas, mal-amadas e antihomens.

As antifeministas, diferente das feministas, argumentavam que se a mulher assumisse funções socialmente masculinas, ela desenvolveria características inapropriadas e incompatíveis com a natural função primeira da mulher "a maternidade" (VANIN, 2011, p. 166). Por receio de serem rejeitadas ou rechaçadas socialmente, algumas mulheres que pertenceram ao Feminismo de Primeira Onda não afirmaram para si o título de feminista (DUARTE, 2003).

Mesmo tendo lutado durante anos pela emancipação feminina da época, muitas mulheres não queriam ser associadas ao estereótipo de feminista, definir-se como feminista no Brasil era um grande risco (PEDRO, 2013). No pensamento social, a mulher se tornaria fria, mundana, imoral e estaria fugindo do que foi "estabelecido pela natureza" caso se tornasse feminista (VANIN, 2011, p. 167). E mesmo recusando tal título, muitas mulheres 
ainda foram perseguidas socialmente, como foi o caso de Nísia Floresta que se mudou para a Europa após ser vítima da imprensa. No exílio a escritora se tornou amiga de Auguste Comte (1798-1857) e morreu na França em 1885 (TELLES, 1993).

\section{A ESCRITA LITERÁRIA COMO ESTRATÉGIA DE MILITÂNCIA}

A escrita de mulheres da elite era comumente incentivada pela família e pela Igreja em alguns gêneros específicos como as cartas, os livros de receita e os diários. A carta era um gênero muito feminino, as mães eram as grandes escritoras do lar. Elas escreviam para os parentes mais velhos, para o marido na guerra, para o filho adolescente no colégio interno, para a filha casada ou as amigas de convento.

A carta constitui uma forma de sociabilidade e de expressão feminina, autorizada, e mesmo recomendada, ou tolerada. Forma distanciada do amor, mais conveniente e menos perigosa do que o encontro, a carta de amor toma o lugar do próprio amor, a ponto de representar o essencial. Torna-se um tema e um motivo da literatura (no romance epistolar) e da pintura de gênero, principalmente a pintura holandesa. A mulher que lê uma carta em seus aposentos, ou perto de uma janela, na fronteira entre o interior e o exterior, sonha com o amante ou o marido viajante ou guerreiro (PERROT, 2007, p. 29).

As correspondências femininas privadas eram raramente publicadas, apenas quando descreviam ou colocavam em cena homens importantes na política ou na sociedade. A escrita de um diário também era um exercício recomendado, principalmente pela Igreja Católica que o considerava um instrumento de direção de consciência e de controle pessoal.

Segundo Perrot (2007), outro problema relacionado à falta de escritos femininos na História se encontra na destruição que as mulheres faziam de suas produções. Ao prever a indiferença e a negligência dos herdeiros, a maior parte das mulheres ao chegar à velhice, punham suas coisas em ordem, selecionavam as correspondências e queimavam as cartas de amor, os diários, e todo o tipo de testemunha escrita das emoções, esperanças e sofrimentos, sua forma de ser e pensar. Isso ocorria principalmente quando esses escritos colocavam em risco a honra e a moral da mulher que escreveu. 
A escrita em jornais, mesmo que em jornais masculinos, equivalia ao ingresso no grupo dos cidadãos ativos da sociedade, dava a algumas mulheres o aval para frequentar ambientes de predominância masculina, discursar sobre política e defender a educação igualitária para moças e rapazes. Porém, nem todas as mulheres podiam disputar a vaga na inserção social que vinha dos periódicos, eles eram mais acessados pela elite. Isto em função do custo e da alta taxa de analfabetismo das camadas populares. Entretanto, foram o início da formação de uma classe feminina privilegiada e leitora de jornais.

Os jornais, portanto, passavam a convidar a face mais privilegiada do gênero feminino, isto é, as mulheres letradas, conforme as palavras do Espelho Diamantino "as mais habeis" ou no discurso do O Mentor das Brasileiras as "estudiosas Brasileiras", a passarem algum tempo durante os dias lendo suas folhas repletas de instrução (política, cívica, moral...), de argumentos contra a malícia de seus detratores e de entretenimento (novidades literárias, moda...) (GOMES, 2009, p. 26).

O perfil das leitoras e escritoras nesse período era quase padrão: elas eram mulheres cultas e educadas, com predominância branca e de classe média alta. Só por terem tido acesso à educação já eram distintas da grande parte das mulheres da época. Além de dominarem bem a leitura e a escrita, e terem tido tempo disponível para se dedicarem a outros afazeres que não fossem os domésticos. Muitas vezes, as escritoras recebiam influências de pais, maridos ou irmãos jornalistas (CASADEI, 2011).

O discurso sobre a "natureza feminina", que foi formulado durante o século XVIII e se impôs na formação social da burguesia em ascensão, definiu a mulher como maternal/delicada e como destruidora/maligna, ambos ao mesmo tempo. Quando a mulher era obediente aos padrões culturais, ela era vista como um anjo do bem, mas quando usurpava as atividades que não lhe eram culturalmente concedidas, era taxada como uma força do mal (TELLES, 2004).

Esse discurso que deu natureza ao feminino o colocou além ou aquém da cultura. Assim, a criação da prole foi definida como um direito dos homens, enquanto cabia às mulheres apenas a reprodução humana e sua nutrição. Com a difusão da vida cotidiana através dos romances e de outros gêneros literários durante o século XIX e XX, alguns aspectos tidos como "naturais" do feminino foram incorporados pela literatura, eles se tornaram um auxílio para a propagação e consolidação da família tradicional burguesa. 
Desse modo, o romance, junto com outros gêneros literários, foi associado à figura feminina nesse período; as características tidas por inatas da mulher, como a sensibilidade, a irracionalidade e a emoção, juntamente com a imposição do amor romântico como um fator constitutivo e essencial da identidade feminina foram vinculadas às mulheres da época. (RAFAEL, 2012).

A escrita literária predominante nas matérias assinadas por mulheres ou pseudônimos, selecionava o público feminino como alvo de leitura nos jornais masculinos. Visto que tais gêneros literários comprovavam a invirilidade dos sujeitos, em nome da honra e da masculinidade, os homens repudiavam esse tipo de leitura e deixaram o espaço aberto para que algumas escritoras transmitissem às leitoras as pautas próprias da primeira onda feminista.

Existiam duas vertentes distintas de escrita feminina em jornais no Brasil: o pudor, e o desnudamento. O pudor reforçava os padrões sociais da mulher mãe-esposa e por isso teve menos resistência que o desnudamento, que veio chocando a sociedade com a luta pela emancipação da mulher emanada dos movimentos feministas (SOIHET, 1997).

[...] as feministas têm consciência do papel da imprensa na opinião pública. Elas tomam essa tribuna com profissionalismo e também com muito idealismo. Recusando-se, por exemplo, a adotar o sobrenome do marido [...] põe em primeiro plano a reivindicação dos direitos civis (direito ao divórcio) e da liberdade, sentimental, amorosa, sexual [...] (PERROT, 2007, p. 15).

O fenômeno da publicação e da leitura de contos e poemas no jornal alcançou proporções extraordinárias na vivência diária e no imaginário das leitoras. Desenvolveu o estimulo sociocultural necessário tanto para a imprensa feminina que espalhava seus ideais, quanto para as mulheres que buscavam um meio que desse voz às suas causas e inserção social. Chega a ser estranho, mas é real, foi o machismo da época que propiciou um caminho livre para que as ideias de emancipação feminina circulassem nos jornais e alcançassem as mulheres da elite sem censura, e depois, no XX e XXI, não só as da elite.

\section{UMA MULHER FEITA COM FLORES DE AÇO}


Mais conhecida como Lulurde, Maria de Lourdes Teixeira foi uma mulher quase comum que, junto com várias outras, contribuiu do Brasil, interior de Minas Gerais, com a Primeira Onda Feminista. Ela, filha da doméstica Maria Cimeliana de Campos Teixeira e do farmacêutico Ananias Ataliba Teixeira, nasceu em 18 de Novembro de 1905 no município de Abadia, no interior de Minas Gerais (cidade no qual adotou o nome de Martinho Campos em 1938).

Lulurde se casou com o engenheiro Osvaldo Machado Gontijo, mas não assumiu o sobrenome do marido após o casamento, estudou o magistério em São João Del Rey (Minas Gerais) frequentou a Escola de Aperfeiçoamento em Belo Horizonte e em meados de 1931 se tornou a primeira diretora com formação específica em Divinópolis. Professora, diretora e escritora do jornal A Estrella da Oeste, Maria de Lourdes deixou uma trajetória de luta pelos direitos das mulheres na cidade de Divinópolis.

Maria de Lourdes gerou uma descendência de cinco filhos e três filhas: Odilon, Fausto, Helena, Daniel, Galileu, Raimundo, Elaine e Ângela. Todas as filhas seguiram o caminho do magistério da mãe, porém morreram muito jovens. Em 2017, havia apenas uma descendência direta de Lulurde, seu filho do meio: Galileu Teixeira Machado já com 85 anos. Lulurde foi diretora da Escola Estadual Padre Matias na cidade de Divinópolis durante os anos de 1932 a 1943. A professora veio a falecer no dia 05 de Maio de 1996 de morte natural aos 91 anos em sua própria casa, em Divinópolis. Atualmente (2018), há em sua homenagem a Rua Maria de Lourdes Teixeira, no bairro Manoel Valinhas em Divinópolis, e a Escola Municipal Professora Maria de Lourdes Teixeira, no bairro Dona Rosa, também em Divinópolis.

\section{MILITÂNCIA ATRAVÉS DOS JORNAIS}

A forma que Lulurde encontrou para disseminar suas ideias e reivindicar direitos para as mulheres foi através da escrita em jornais. Aos 17 anos, Maria de Lourdes começou a escrever colunas no jornal A Estrella da Oeste que era veiculado em Divinópolis, cidade do Centro-Oeste mineiro. O jornal foi iniciado no dia 7 de Setembro de 1922, teve circulação quinzenal e contou com a escrita de Lulurde e outras mulheres desde a sua segunda edição, 


\section{Revista
Debates Insubmissos}

em 24 de Setembro de 1922. A escrita feminina de A Estrella da Oeste muito se assemelhava às escritas emancipadoras das feministas de Primeira Onda.

Na segunda edição, o jornal estreou uma sessão reservada chamada Sessão Feminina onde Joaninha Coelho escreveu sua primeira carta chamada À minha querida mãe adoptiva. Na carta, Joaninha escreve à sua mãe de criação demonstrando um grande carinho e amor por ela, agradecendo-a por todo tempo que lhe foi dedicado, a boa criação que teve e ao amor ofertado por ela. "É a ti, meigo anjo, única esperança dos meus dias futuros, a quem offereço esse pequeno trabalho symbolo do amor ardente e dedicado que te consagro [...]" (COELHO, 1922, 2ed., p. 2).

Na terceira edição desse jornal, a Sessão Feminina trouxe a matéria Educação na Infância de Maria de Lourdes Teixeira assinada pelo pseudônimo de M. L. Teixeira. Sobre os pseudônimos na escrita feminina, Duarte diz que:

O mesmo veículo que acolheu os textos das escritoras, inicialmente sob pseudônimos masculinos e mais tarde assumindo a autoria própria, também foi palco de críticas e preconceitos em relação à mulher de letras, principalmente àquelas que não se enquadraram no modelo padrão de mulher a ser seguido. (DUARTE, 2009, p.14).

Maria de Lourdes inicia a Sessão Feminina dizendo que "não devemos descuidar da formação do caráter e do desenvolvimento do germem do bem no coração das creanças e termina o artigo afirmando que [...] a professora, na escola, a aperfeiçoará dando lhes bons conselho" (TEIXEIRA, 1922, 3ed., p. 2). Na medida em que no período a educação masculina era a mais vigente e aceita socialmente e diante de todos os escritos de Maria de Lourdes é possível levantar a hipótese de que a utilização da palavra "creanças" em sua matéria, era uma forma proposital, mas sutil, de defender a educação igualitária para ambos os gêneros e não apenas a educação masculina. Não se sabe se, nesse período, Maria de Lourdes já era professora, porém cabe ressaltar sua preocupação com a boa formação educacional das crianças.

A quarta edição do jornal, em 12 de Outubro de 1922, contou com uma poesia de Joaninha intitulada A Esperança. A escritora começa sua poesia dizendo que: “A esperança é 


\section{Revista
Debates Insubmissos}

o sol que ameiga e desata a flôr para que rescenda o doce aroma; que acorda as arvores para que espiritualize os bosques” [...] (COELHO, 1922, 4ed., p. 3).

De todas as escritoras desse jornal, Joaninha foi a que mais possuiu uma escrita ligada ao pudor, enaltecendo as características tidas como femininas. Ela utilizava de simbologias relacionadas à mulher-mãe como a sensibilidade, a gentileza e a demonstração de sentimentos em seus textos literários e, dessa forma, chamava a atenção das mulheres da época para seus escritos. A escrita pudorada de Joaninha não significava que ela se opunha aos ideários feministas da época, ao contrário, como uma grande amiga de Lulurde, em uma de suas cartas elas se identificam com “irmãs no pensar” (COELHO, 1922, 10 ed., p. 1).

O texto Recordações, assinado pelo pseudônimo L., esteve presente na sexta edição do jornal em 29 de Outubro de 1922 e relata os sentimentos próprios de uma mulher; a saudade que a mesma sentia do colégio onde estudou, mesmo após terem se passado três anos. Nem a alegria de reencontrar os pais e poder abraçá-los, não foi suficiente para apagar a melancolia saudosa das amigas do colégio e das caritativas almas:

E tanta melancolia era causada pela saudade do collegio, onde passei um lustro em convívio com dedicadas amiguinhas e caridosas Irmãs. Essa saudade, que tanto cruciava o meu coração, era sincera, pois o tempo destruidor, em três longos annos, ainda não conseguio siquer amortecel-a! (L., 1922, 6ed., p.2).

A sétima edição do jornal contou com duas poesias distintas: uma na primeira página intitulada $\mathrm{O}$ Perdão, assinada por Joaninha Coelho, e outra na segunda página intitulada $\mathrm{O}$ Beijo, assinada por P. Em O Perdão, Joaninha faz uma abordagem voltada ao romance e ao sentimentalismo sobre o ato de perdoar: "O que é o perdão? O perdão é o symbolo do amor, o emblema da caridade, o protesto da affeição!...” (COELHO, 1992, 7ed., p. 1).

Já em $\mathrm{O}$ Beijo, a escritora que utilizou o codinome $\mathrm{P}$. escreveu com menos sentimentalismo que Joaninha e ainda utilizou frases que, sutilmente, remeteram ao erotismo: "Dizem que o beijo estonteia. Acende extranho calor, e do sangue, em nossa veia, instila o morbus do Amor. Beijo!... lábios úmidos na mais perfeita união[...]”(P., 1922, 7ed., p. 2).

Na oitava edição do jornal, o pseudônimo L. escreve o texto Amisade Á Joaninha. Nessa texto, L. declara toda sua amizade e seu apoio a Joaninha, afirmando os sentimentos de amor e companheirismo pela mesma e ressalta: “[...] como é bello ver-se duas amigas, irmãs 
no pensar, alimentando os mesmos sentimentos." L. afirma publicamente a amizade entre duas dizendo:

É-nos a vida mais triste e espinhosa quando não temos a quem dedicar uma sincera afeição. Quando não podemos calar por mais tempo o que temos n'alma e sentimos necessidade de abrimos o nosso coração a alguém, sermos felizes [...] Conhece-se quaes são as verdadeiras amigas, quando a sorte nos torna menos favorável; as que tem o coração coberto com o negro manto da hypocrisia, fogem com a felicidade, deixando-nos entregues aos sofrimentos!... (L., 1922, $8^{\circ}$ ed., p.1).

Assim, é importante ressaltar que Lulurde e Joaninha mantinham entre si uma relação de amizade muito próxima. Elas se conheciam antes da circulação dos periódicos, interagiam suas escritas no mesmo, e encontravam força e proteção uma na outra. Isso foi muito comum durante a primeira onda feminista. As escritoras feministas do período formaram uma rede feminina de comunicação e amizade através dos jornais, interagindo e divulgando os trabalhos uma das outras (PINTO, 2003; TELLES, 1993). Lulurde e Joaninha, em especial, se viam como "irmãs no pensar" e buscaram incentivar a escrita de outras mulheres no jornal.

A resposta de Joaninha veio na décima edição e estampou a primeira capa do jornal: O Amor e a Amisade; À minha querida amiga e colega, Lourdes - em retribuição ao artigo que me foi dedicado. Nessa carta, Joaninha reafirma a amizade e as convicções entre as escritoras e diz: "quanto é bom comprehender-se e ser-se comprehendida...! Isto é o ideal...! Quanto é sublime ser uma por duas e duas por uma, pois se a união faz a força!." (COELHO, 1922, 10 ed., p. 1). Em seguida, a escritora distingue os sentimentos amor e amizade, e afirma que a amizade é superior e mais rara. Nessa resposta também, descobrimos mais um pseudônimo de Maria de Lourdes: L.

A Sessão Feminina do jornal A Estrella da Oeste se encerrou na quarta edição, em 1922 com a poesia A Esperança de Joaninha. Entretanto, a participação das mulheres através da literatura (contos, poesias, poemas e cartas) aumentou nas edições posteriores chegando inclusive a estampar algumas vezes a primeira página do jornal como uma das matérias principais. Os textos emancipatórios de Maria de Lourdes vieram com força total após o fim da Sessão Feminina. 


\section{MARIA DE LOURDES TEIXEIRA E SUAS CONTRIBUIÇÕES PARA A PRIMEIRA ONDA FEMINISTA}

Durante o primeiro ano de circulação do jornal A Estrella da Oeste, momento inicial do periódico, é possível perceber que a escrita feminina permeava o pudor. As escritoras utilizaram os gêneros literários de forma concisa e reforçavam as características tidas do feminino como a sensibilidade, o amor, o sentimentalismo e o recato; sem fazer nenhuma afronta à condição social das mulheres, à moral ou aos costumes da época. Mesmo Maria de Lourdes, que escreveu apenas poesias, utilizou os pseudônimos L. e M. L. Teixeira para resguardar sua verdadeira identidade.

Porém, isso começou a mudar na décima quarta edição do jornal, em 15 de Abril de 1923, quando Lulurde assinou seu primeiro conto no jornal, expondo sua identidade. O conto chamado Os homens são assim! é extenso e conta uma história não muito comum para a época. A história de Walter foi narrada: um moço louro, ajuizado e de alta linhagem que possuía pouco afeto ao casamento e muita entrega a boemia. Na história, Walter se apaixonou por Zenália, uma moça retraída, recatada e educada que discutia com boa lógica filosófica e a propôs casamento.

Durante a viagem para a compra de seu enxoval de casamento no Rio de Janeiro, Walter conheceu Aida, uma jovem atirada que no primeiro encontro o convidou para encontrá-la sozinha em sua casa. Os dois passearam sozinhos de carro durante 15 dias, e no final, Walter deu todo o seu amor à Aida e a propôs casamento. $\mathrm{O}$ conto termina com o encontro de Walter e Zenália dizendo: "E Walter virou-lhe as costas, e dois dias depois voltava para o rio, onde se casou com Aida, deixando Zenália que era boa, santa e pura. Os homens são assim!...” (LULURDE, 1923, 14 ed., p. 2-3).

Os homens são assim! foi um conto fundamental para o início da escrita emancipada e desnudada no jornal de Maria de Lourdes em A Estrella da Oeste. Pela primeira vez, foi-se veiculada uma história onde ser santa, boa e pura era sinônimo de demérito, e o final feliz esteve em favor de uma mulher depravada e "da vida". A moral da história escrita por Lulurde confrontava a moral da época e tudo o que era ensinado pela Igreja, pelas famílias e pelo 


\section{Revista
Debates Insubmissos}

próprio Estado, e deixava como problemática final o inútil sacrifício moral das mulheres para conquistar maridos.

Após o conto Os homens são assim!, Maria de Lourdes Teixeira escancarou a porta da luta pela emancipação das mulheres e começou a lançar de forma aparente os ideais da primeira onda do Feminismo em seus escritos. Na edição décima quinta edição do jornal, ela trouxe a tona o conto chamado: Mal sem remédio. Nesse conto ela escreve à Maria, sua amiga, dizendo o quanto é desagradável à vida de casada e o quanto foi enganada pela sociedade sobre o casamento e sobre seu marido Tião.

Lulurde recomenda que Maria nunca se case e afirma que "a vida de solteira é cheia de prazeres, felicidades e liberdade enquanto o casamento a tornaria escrava dela mesma”. (LULURDE, 1923, 15ºd., p. 2-3). A escritora também disse que seu casamento era bom no início, mas depois se tornou uma completa tortura. Nomeou o marido de bêbado e boêmio, alegou que há treze meses não via os pais, afirmou diversas vezes seu arrependimento mortal em ter se casado e conclui dizendo: "Finalmente, é isso que chamam de casamento, um suicídio lento, nada mais." (LULURDE, 1923, $15^{\circ}$ ed., p. 2-3).

Não se sabe em que medida esse conto é baseado na história real da vida de Lulurde ou se foi um conto fictício para levantar os questionamentos sobre o casamento, que na época, era forçado pelas famílias. Porém, é perceptível a maneira aberta com que Lulurde aborda o casamento, que era um tema tabu naquele momento, se posicionando contrária ao mesmo e enaltecendo a liberdade das mulheres solteiras.

O conto Mal sem remédio causou um grande tumulto na sociedade, como foi descrito no conto seguinte. A discordância se deu principalmente pelas mulheres, e não pelos homens, que leram tal coluna e se opuseram ferrenhamente ao posicionamento de Lulurde sobre o casamento. Isso confirma que eram as mulheres letradas o público leitor das colunas femininas e não os homens. Assim, na vigésima segunda edição do jornal, Lulurde escreveu em sua defesa o conto Pelo Casamento dizendo:

Certamente não deixaram de se horrorizar, um tanto, as minhas irmãs de sexo, com o ultimo conto de nossa "Estrelinha" que [...] pôs algumas verdades a luz do sol, sobre o casamento infeliz, tão frequente em nosso 


\section{Revista \\ Debates Insubmissos}

meio social, cujo o organismo já se acha bastante inoculado desse terrível vírus. (LULURDE, 1923, $22^{\circ}$ ed., p. 1-2)

Nesse conto Lulurde demonstra sua relação com o movimento feminista da época ao usar a expressão irmãs de sexo, visto que a palavra gênero e suas concepções ainda não estavam em pauta. Ela também assume a autoria de seu conto anterior, afirma não se arrepender de nada que escreveu e acrescenta:

[...] De resto, o edifício do casamento não pode continuar a ser feito sobre os princípios actuaes que pouca ou nenhuma vantagem nos oferecem: - ser-se escolhia por um homem, e não termo o direito de dizer-lhe que não é ele o que representa o nosso ideal, com o receio de ficarmos para tia?... Isso é sermos pequenas demais, é falta de confiança em nós mesmas!... Porque só o homem pode garantir o futuro de uma família ou de uma mulher? Por acaso ele não é mortal como todos os seres vivos? Até onde há chegado a mulher que inerte que somos! Não devemos pois aceitar mais essa anomalia social, mas trabalharmos unidas para nossa emancipação[...] (LULURDE, 1923, $22^{\circ}$ ed., p. 1-2)

Além disso, Lulurde defendeu a emancipação das mulheres através da instrução, falou sobre o analfabetismo feminino e citou algumas companheiras nos Estados Unidos que alcançaram sua independência financeira através dos estudos nas carreiras de juíza e advogada e detetive:

A comunhão de idéas que se voltam isochronas para um só ponto, tem que triumphar sempre, e nós teremos que conseguir isso é pela instrução da classe, que infelizmente fornece ainda grande material na cifra das porcentagens sobre o a analfabetismo. Como conseguiram subir as nossas companheiras Mlle. Fanny Sewald, Mrs. Florence E. Allen (juiz do supremo tribunal de Ohio - E. Unidos) e Mrs. Nina van Winkle (detetive de Washington)? Com instrucção, nada mais. (LULURDE, 1923, $15^{\circ}$ ed., p. 2-3).

Ela afirmou que a sociedade precisava se pautar na escolha livre do amor; que as mulheres precisam ter o direito de escolher seus maridos e trabalhando, contribuir com eles no sustento da família para que não sofram com a dependência financeira dos mesmos. Esse mesmo conselho, segundo seu filho Galileu, Lulurde dava à suas três filhas.

De resto, não sou contra o casamento, e sim do sistema baseado nos princípios despóticos da Igreja e do Estado que querem dotar a natureza 


\section{nevistet \\ Debates Insubmissos}

como um costume imutável e sempre fixo. Urge, pois, cogitarmos da mudança desse systhema, sucedendo-o por um mais inteligente e acceitável, falicitando-nos o direito dos direitos: escolhermos o eleito de nosso coração e collaborarmos com ele nostrabalhos da vida, habituando-nos no ganha pão, para assim, não recearmos o dia de amanhã. (LULURDE, $1923,15^{\circ}$ ed., p. 2-3).

Por fim, Lulurde discursou sobre a seleção sexual e afirmou que o casamento se tornou apenas um pacto entre dois "cheques vitaes", não sendo raro um espetáculo de sangue. Para mudar essa realidade, Lulurde apostava na emancipação das mulheres e na igualdade dos direitos:

Então, como resolver esta questão da vida conjugal em este planeta que habitamos? Muito simples. Emancipemos a mulher, dando-lhe alguma luz, senão bastante direitos iguais aos dos homens, onde ela possa ser independente, livre e modifiquemos, desde já, o código do casamento em todas as suas imperfeições. Porque só ao homem é reservado o direito de fazer a sua escolha amorosa? Por acaso não achamos João melhor que Pedro? Sim, esse privilegio precisa ser nosso também. No dia que isso acontecer, deixaremos de ser uma mercadoria exposta a venda para o primeiro que passa e faz boa oferta [...] E ter-se medo do celibato, cujo verso da medalha é o horrível: - "ficar para tia", com o que nada perdemos, pois não é tão comum nos homens? (LULURDE, 1923, $15^{\circ}$ ed., p. 2-3).

Lulurde afirma que os casamentos "se desenrolam tristemente pelos tribunaes de um paiz que não sabe interpretar o valor do divórcio, remédio único para o engano dos conjugues". (LULURDE, 1923, $15^{\circ}$ ed., p. 2-3). É importante ressaltar que a lei do divórcio no Brasil só foi aprovada em 1977, ou seja, ao menos 54 anos antes de tal aprovação (pegando pela data da publicação do jornal), as feministas brasileiras já levantavam a pauta do divórcio legal e lutavam pela liberdade dos matrimônios.

Lulurde conclui seu texto pedindo liberdade para a escolha dos companheiros e dizendo que há inúmeras pessoas arrependidas que sofrem caladas os casamentos infelizes, no qual ela chama de a dor sem remédio de um mal sem cura. Após essas declarações, a escrita literária desapareceu completamente jornal A Estrella da Oeste, assim como a escrita através de pseudônimos femininos. O jornal adotou um caráter bastante político e descritivo. Em 1924, algumas edições contaram com poesias e contos, mas todas foram assinadas por homens. 


\section{Revista \\ Debates Insubmissos}

\section{CONSIDERAÇÕES FINAIS}

A título de considerações finais queremos ressaltar a importância da primeira onda feminista para a conquista dos direitos básicos das mulheres no Brasil e no mundo. Foi nesse momento que o feminismo começou a se organizar quanto movimento social e algumas mulheres começaram a adquirir consciência de seus direitos e de seu lugar na sociedade. Ainda que passeatas e manifestações públicas tenham sido feitas, a principal estratégia de militância adotada pelas feministas da época foram as letras: o jornal, as cartas, o magistério e os salões de leitura. É nesse sentido que os jornais ganham um grande destaque ao se tornar uma rede de comunicação e interação, por vezes feminina, por onde as ideias circulavam.

Contudo, o perfil socioeconômico da maior parte das mulheres que compuseram a primeira onda feminista era um tanto excludente: mulheres letradas, cultas, de predominância branca e de classe média alta; só por terem tido acesso à educação naquele período, já se distinguiam da maior parcela das mulheres que tiveram o seu acesso à educação por algum motivo negado. Além disso, essas mulheres tiveram tempo disponível para despender com atividades fora dos afazeres domésticos e dos trabalhos manuais típicos da classe social mais pobre. Isso mostra um feminismo, de certa forma, elitizado, mas que ainda assim foi importante para a conquista dos direitos das mulheres a curto e longo prazo, sendo também o "pontapé" inicial de um movimento que se desenvolveu através de diferentes ondas e se empenha até os dias atuais.

Nessa perspectiva, embora o jornal A Estrella da Oeste abordasse o contexto patriarcal típico do período, com manchetes de porte "viril" escrito por homens e direcionado ao público masculino, a abertura que este jornal ofereceu às mulheres na sua primeira fase foi muito importante para a luta feminina e para a disseminação das ideias feministas na pequena cidade mineira. Através dos contos e poesias, que pouco importava para os homens, reflexões e posicionamentos valiosos foram semeados no jornal sem muito aguçar a curiosidade e a censura masculina. Maria de Lourdes Teixeira, através do uso das letras, travou uma luta em favor de direitos e liberdades. Sua luta pela emancipação das mulheres começou nos jornais e se desenvolveu através da educação, como professora e, posteriormente, como diretora escolar. 


\section{REFERÊNCIAS:}

BANDEIRA, Lourdes; MELO, Hildete Pereira. Memórias das Lutas Feministas no Brasil. In: Tempos e Memórias do Feminismo no Brasil. Brasília: Secretaria de Políticas para as Mulheres - SPM, 2010.

BEAUVOIR, Simone. Le Deuxième Sexe, Paris, Gallimard, 1949.

BÍBLIA DE JERUSALÉM. 1 Timóteo, capítulo 2, versículos de 8 a 15. São Paulo: Paulus Brasil. 2000.

BOURIDEU, Pierre. A Dominação Masculina. Tradução: Maria Helena Kühner. - $11^{\circ}$ ed. Rio de Janeiro: Bertrand Brasil, 2012.

CAPELATO, Maria Helena Rolim. A imprensa na história do Brasil. São Paulo: Contexto/EDUSP, 1988.

CASADEI, Eliza Bachega. A inserção das mulheres no jornalismo e a imprensa alternativa: primeiras experiências do final do século XIX. Revista Alterjor, Grupo de Estudos Alterjor: Jornalismo Popular e Alternativo (ECA-USP). Ano 02- Volume 01 Edição 03 - JaneiroJunho de 2011.

CASTRO, Mary Garcia. Marxismo, feminismos e feminismo marxista - mais que um gênero em tempos neoliberais. Crítica Marxista, n. 11, São Paulo, p. 98-108, 2000. (Dossiê Marxismo e Feminismo).

CERTEAU, Michel de. A Escrita da história. Rio de Janeiro: Forense Universitária, 1982.

COSTA, Ana Alice A. O Movimento Feminista no Brasil: dinâmica de uma intervenção política. In: MELO, H. P et al (ORG). Olhares Feministas. Brasília: Ministério da Educação: UNESCO, 2006.

.; SARDENBERG, Cecília Maria B. Feminismos, feministas e movimentos sociais. In. BRANDÃO, Maria Luiza e BINGEMER, Maria Clara (org). Mulher e Relações de gênero. São Paulo: Loyola, 1994.

.; SARDENBERG, Cecília Maria B. O feminismo no Brasil: uma (breve) retrospectiva. In: COSTA, Ana Alice A.; SARDENBERG, Cecília Maria B (ORG). O Feminismo do Brasil: reflexões teóricas e perspectivas. Salvador: UFBA / Núcleo de Estudos Interdisciplinares sobre a Mulher, 2008.

COSTA, Suely Gomes. Onda, rizoma e sororidade como metáforas: representações de mulheres e dos feminismos. (Paris, Rio de Janeiro: anos 70/80 do século XX). Revista IINTERThesis, Florianópolia, vol. 6, nº 2, 2009. 
DAVIS, Angela. Mulheres, raça e classe [recurso eletrônico]; tradução Heci Regina Candiani. - 1. ed. - São Paulo : Boitempo, 2016.

DUARTE, Constância de Lima. Feminismo e Literatura no Brasil. Estudos Avançados, São Paulo, v. 17, n. 49, p. 81-90, 2003.

; PAIVA, Kelen Benfenatti. A mulher de letras: nos rastros

de uma história. Ipotesi, Juiz de Fora, v. 13, n. 2, p. 11 - 19, jul./dez. 2009.

DUBY, GEORGES DUBY; PERROT, Michelle. Images de femmes. Paris: Plon, 1992.

GOMES, Gisele Ambrósio. Entre o público e o privado: a construção do feminino no Brasil dos oitocentos, 1827-1846. 140 p. Dissertação (Mestrado em História) - Universidade Federal de Juiz de Fora, Minas Gerais. 2009

HAHNER, Jane E. A Mulher Brasileira e suas Lutas Sociais e Políticas: 1850 1937. São Paulo: Brasiliense, 1981.

HEGEL, Friedrich. A Filosofia do Direito. São Leopoldo: Unisinos, 2010.

IANNI, Octavio. A crise de paradigmas da Sociologia. Revista Brasileira de Ciências Sociais (RBCS), n.13, 1990.

KRISTEVA, Julia. Les temps des femmes. Cahiers de Recherche en Sciences des Textes et Documents, Paris, n. 5, p 33-44, 1979.

LIPOVESTKY, Gilles. Os tempos hipermodernos. São Paulo: Editora Barcarolla, 2004.

MACHADO, Lia Zanotta. Feminismo, Academia e interdisciplinaridade. In: COSTA, A. de O.; BRUSCHINI, C. (orgs.). Uma questão de gênero. Rio de Janeiro: Rosa dos Tempos/São Paulo: Fundação Carlos Chagas, 1992. p. 24-38.

MADURO, Daniela. Entre textões e escritões: a narrativa projetada. In: PEIXINHO, Ana Teresa; ARAÚJO, Bruno (orgs.). Narrativa e media géneros, figuras e contextos. Imprensa da Universidade de Coimbra, 2018.

MARQUES, Teresa Cristina N. Elas Também Desejam Participar da Vida Pública: várias formas de participação política feminina entre 1850 e 1932. In: MELO, H. P et al (ORG). Olhares Feministas. Brasília: Ministério da Educação: UNESCO, 2006.

MICHELET, Jules. La femme. Paris: Flammarion, 1981.

MUZART, Zahidé. Feminismo e literatura ou quando a mulher começou a falar. In: PINTO, Celi Regina Jardim. Uma História do Feminismo no Brasil. São Paulo: Fundação Perseu Abramo, 2003. 
Feminismo, História e Poder. Revista de Sociologia e Política,

Curitiba, vol. 18, $\mathrm{n}^{\mathrm{o}} \quad 36, \quad$ Jun. 2010. Disponível em:
<http://www.scielo.br/scielo.php?pid=S0104-44782010000200003\&script=sci_arttext $>$. Acesso em 05 jun. 2017.

PEDRO, Joana Maria. Traduzindo o debate: o uso da categoria gênero na pesquisa histórica. História, São Paulo, v.24, N.1, P.77-98, 2005.

O Feminismo de "Segunda Onda". Corpo, Prazer e Trabalho. In PERROT, Michelle. Minha história das mulheres. São Paulo: Contexto, 2007.

Janeiro: Paz e Terra, 1988.

Os Excluídos da História: Operários, Mulheres e Prisioneiros. Rio de

PINSKY, Carla Bassanezi; PEDRO, Joana Maria (Org.). Nova História das mulheres no Brasil.1. ed., $1^{\text {a }}$ reimpressão. São Paulo : Contexto, 2013.

PINTO, Celi Regina Jardim. Uma História do Feminismo no Brasil. São Paulo: Fundação Perseu Abramo, 2003.

PROUDHON, P.J. De la Justice dans la Révolution et dans l'église. Paris: Garnier Frères, 1858,3 vols., p.348.

RAGO, Margareth. Os feminismos no Brasil: dos "anos de chumbo" à era global. Labryz,

Estudos Feministas, Brasília. n. 3, jan./jul., 2003. Disponível em: <http://www.unb.br/ih/his/gefem/ labrys3/web/bras/marga1.htm> Acesso: 6 fevereiro 2017.

RAFAEL, G. G. Jornais, romance-folhetim e a leitura feminina no século XIX: influências transatlânticas?. IRIS - Revista de Informação, Memória e Tecnologia, v. 1, n. 1, p. 32-42, 2012. Disponível em: <http://www.brapci.ufpr.br/brapci/v/a/18181>. Acesso em: 10 Ago. 2017.

SOIHET, Rachel. História das mulheres. In: CARDOSO, C. F.; VAINFAS, R. (Org.). Domínios da História. Rio de Janeiro: Campus, 1997.

Feminismo ou feminismos? Uma questão no Rio de Janeiro nos anos 1970/1980. In: Seminário Internacional Fazendo Gênero 7, Florianópolis, 2006 (Simpósio Temático: Os feminismos latino-americanos e suas múltiplas temporalidades no século XX).

TELLES, Maria Amélia de Almeida. Breve História do Feminismo no Brasil. São Paulo: Brasiliense, 1993;

TELLES, Norma. Escritoras, Escritas, Escrituras. In: PIORE, Mary (Org.). História das mulheres no Brasil. 7. ed. - São Paulo : Contexto, 2004. 
THOMPSON, John B. Ideologia e cultura moderna: teoria social crítica na era dos meios de comunicação de massa. Petrópolis: Vozes, 2002.

VANIN, Iole Macedo. Feminismo Verso "Anti-feminismo" Embates Baianos. In: BONNETI, Alinne; SOUZA, Ângela Maria Freire Lima (Org.). Gênero, Mulheres e Feminismos. Salvador: EDUFBA: NEIM, 2011.

ZICMAN, Renée Barata. História Através da Imprensa - Algumas Considerações Metodológicas. Revista História e Historiografia. São Paulo, n. 4, p. 89-102, jun. 1985.

ZIRBEL, Ilze. Estudos Feministas e Estudos de Gênero no Brasil: Um Debate. 212 p. Dissertação (Mestrado em Sociologia Política) - Universidade Federal de Santa Catarina. Florianópolis, 2013.

\section{FONTES DOCUMENTAIS:}

COELHO, Joanninha. A minha querida mãe adoptiva. A Estrella da Oeste. Divinópolis, p. 2. Edição 2, ano I, número 2, 24 setembro 1922. Disponível em:

<http://www.emredes.org.br/mostrafoto.php?fotoid=52717>. Acesso em 30/08/2018.

COELHO, Joanninha. A Esperança. A Estrella da Oeste. Divinópolis, p. 3. Edição 4, ano I, número 4, 12 outubro 1922. Disponível em:

<http://www.emredes.org.br/mostrafoto.php?fotoid=52726>. Acesso em 30/08/2018.

COELHO, Joanninha. O Perdão. A Estrella da Oeste. Divinópolis, p. 1. Edição 7, ano I, número 7, 5 novembro 1922. Disponível em:

<http://www.emredes.org.br/mostrafoto.php?fotoid=52738>. Acesso em 30/08/2018.

COELHO, Joanninha. Amor e Amisade. A Estrella da Oeste. Divinópolis, p. 1. Edição 10, ano I, número 10, 12 dezembro 1922. Disponível em:

$<$ http://emredes.org.br/mostrafoto.php?fotoid=52760 . Acesso em 30/08/2018.

L. Recordações. A Estrella da Oeste. Divinópolis, p. 2. Edição 6, ano I, número 6, 29 outubro 1922. Disponível em: 〈http://www.emredes.org.br/mostrafoto.php?fotoid=52733> Acesso em 30/08/2018.

L. Amisade à Joanninha. A Estrella da Oeste. Divinópolis, p. 1. Edição 8, ano I, número 8, 15 novembro 1922. Disponível em: 〈http://emredes.org.br/mostrafoto.php?fotoid=52743> Acesso em 30/08/2018.

LULURDE. Os Homens são Assim. A Estrella da Oeste. Divinópolis, p. 2 e 3. Edição 14, ano I, número 14, 15 abril 1923. Disponível em:

<http://www.emredes.org.br/mostrafoto.php?fotoid=52857> Acesso em 30/08/2018. 
LULURDE. Mal sem remédio. A Estrella da Oeste. Divinópolis, p. 2 e 3. Edição 15, ano I, número 15, 22 abril 1923. Disponível em:

<http://www.emredes.org.br/mostrafoto.php?fotoid=52874> Acesso em 30/08/2018.

LULURDE. Pelo Casamento. A Estrella da Oeste. Divinópolis, p. 1 e 2. Edição 22, ano I, número 22, 10 junho 1923. Disponível em::

<http://www.emredes.org.br/mostrafoto.php?fotoid=35171> Acesso em 30/08/2018.

P. O Beijo. A Estrella da Oeste. Divinópolis, p. 2. Edição 7, ano I, número 7, 5 novembro 1922. Disponível em: <http://www.emredes.org.br/mostrafoto.php?fotoid=52739>. Acesso em 30/08/2018.

TEIXEIRA, M.L. A educação na infancia. A Estrella da Oeste. Divinópolis, p. 2. Edição 3, ano I, número 3, 01 outubro 1922. Disponível em:

<http://www.emredes.org.br/mostrafoto.php?fotoid=52721>. Acesso em 30/08/2018.

Acervo completo do jornal A Estrella da Oeste disponível em: Em Redes, Portal da Memória do Centro Oeste Mineiro <http://emredes.org.br/index.php>. Acesso em 30/08/2018.

Submetido em: 30/06/2018

Aprovado em: 26/08/2018 